\title{
MOST EFFECTIVE INTERNATIONALLY EMERGING IMPLEMENTATION MODELS IN TEACHER PROFESSIONAL DEVELOPMENT PROGRAMS OVER THE LAST DECADE
}

\author{
Abdulla Al Darayseh, \\ Sultan Al Sadi, \\ Yahia Alramamneh ${ }^{\mathrm{i}}$ \\ Dr., Emirates College for Advanced Education, \\ PO Box 126662, Abu Dhabi, \\ United Arab Emirates
}

\begin{abstract}
:
This study aims to identify effective internationally emerging implementation models in teacher professional development. Several trends in teacher Professional Development are influencing the nature and quality of teacher professional development. The metaanalysis method was used in this study by identifying, collecting, and analysis potential studies to reach the findings. The results show that professional development has the potential to transform the education scene when supported by all industry players. Policy plays a vital role in the success of programs like PD programs. Policies surrounding the government of this model should be carefully structured to guide the PD programs appropriately as well as formulators should be industry players who understand the drivers that affect the education sector and in particular the educators. Good policy choices will mean that the PD stands a chance to be effective. The PD program should be provided with all the necessary resources for it to be effective and to enable smooth running. Educators should be facilitated with the necessary materials they require for the program. Lack of resources means that the PD program will not achieve its intended goals. Resources might be learning resources for the educator, allowances among many others. Extensive collaborations should be done by the sectors that could play a strong role in affecting the education, stakeholders, investors and other parties related in order to reach an agreement on the best model of PD. Additionally, there is a need to determine how best to run the PD programs to be beneficial to the education system.
\end{abstract}

Keywords: professional development, implementation models, teacher, meta-analysis

i Correspondence: email abdulla.aldarayseh@cece.ac.ae, sultan.alsady@cece.ac.ae, yahia.alramamneh@cece.ac.ae 


\section{Introduction}

In the last few decades, the UAE has witnessed a widespread expansion of schools and educational opportunities. Widely acknowledged as the age of "education reform', the nation has experienced a period of extraordinary transformation and growth. The nation has sought to develop educational systems that are in line with global education reform (GERM) initiatives, aiming to improve the quality of education in the MENA region and worldwide. Thus, educational entities have established policies, procedures and curricula aligned to international standards and UAE specific needs, increased access to universal education amongst males and females and reduced illiteracy. All of this has been accomplished through an abundance of government incentives and financial investment.

With such growth, the UAE has placed a high priority on improving the quality of teaching and learning. Indeed, the effectiveness of the UAE education system relies heavily on the effectiveness of its educators. Professional development programs that address the specific needs of educators in the UAE are integral to the success of the education reform.

Globally professional development is an extensively researched topic, with many definitions and structures, in the broad sense it may refer to an individual's development of knowledge and skills in a professional role. More specifically it can be described as, "the professional growth a teacher achieves as a result of gaining increased experience and examining his or her teaching systematically" (Glatthorn, 1995). Teacher professional development is the backbone of any educational system and relies both on gaining experience and receiving appropriate opportunities for impactful training. Especially considering the technological, economic and social gaps, and modern trends in the world, whose impact on education is reflected in all its components and elements (Al-Dossary, 2020).

Teacher professional development in the 21st century has evolved from traditional forms of subject specific knowledge development and the ability to implement prescribed methods, towards more research based, collaborative and situated approaches focused on emerging classroom contexts (Canagarajah, 2015). This shift is based on a more developed understanding of how teachers learn and what pedagogical models most effectively facilitate their professional growth as educators.

In addition, contextualization of professional development programs now receives global focus as schools are seen as "learning organizations that must respond quickly and flexibly to their dynamic environments, with external driving forces" (Sahlberg, 2016), these driving forces can range from governmental changes in curricula, licensing of educators or the current COVID-19 Pandemic. They pose adaptive and transformative challenges in teacher professional development, where content, processes and experiences must be examined.

In order to ensure impactful and purposeful professional development education providers must examine the content, the experiences and the processes by which the 
professional development will occur, and the contexts in which it will take place (Ganser, 2000; Fielding and Schalock, 1985). Thus, this paper seeks to review internationally emerging implementation models in Teacher Professional Development Programs over the last decade.

\section{Research Question}

What are the most effective internationally emerging implementation models in Teacher Professional Development Programs over the last decade (since 2010)?

\subsection{Study Objectives}

The purpose of the study is to identify effective internationally emerging implementation models in teacher professional development.

\subsection{Limitations}

This research review is limited to research produced from 2010 to now, (2020).

\section{Methodology}

The meta-analysis method was used in this study. Meta-Analysis was conducted as a literature review considering conceptually similar studies. The process consisted of collecting, synthesizing, and analyzing research findings from multiple studies.

In this study, the researchers conducted a search of the literature databases. Relevant articles were selected for meta-analysis, reading Titles and Abstracts and full texts from research produced from 2010 onward.

\subsection{Study Design}

The design for this study was built on prior studies in education. The study design has three basic steps as shown in Figure 1:

1) Identification of relevant studies;

2) Pre-Screening \& Data analysis;

3) Reporting and findings. 


\section{Identification and collection of potential studies}

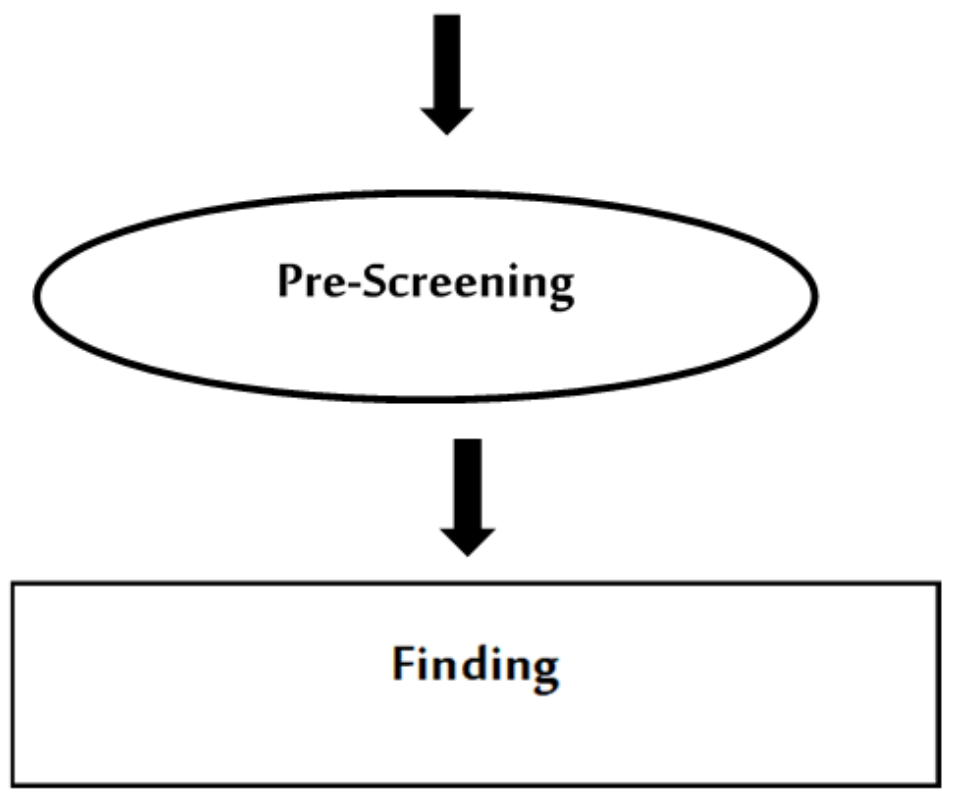

Figure 1: Study design steps

\section{Literature Review}

Several trends in teacher Professional Development are influencing the nature and quality of teacher. PD in the U.S. has moved away from one-time workshops, which in the U.S. have been common. In one-time workshops, teachers meet for 1-3 hours to listen to a lecture on an isolated topic. National data show that in the past couple of decades districts have changed from short 1-3 hour workshops/lectures on an isolated topic of toward PD that attempts to adopt five core features; content focus, active learning, coherence, sustained duration, collective participation (Smith \& Desimone, 2003). For example, analysis of the nationally representative Schools and Staffing Survey shows that fewer than 20\% of U.S. teachers had eight hours or fewer of PD in the 2011-2012 school year (U.S. Department of Education, 2012). A national study of PD in the U.S. showed that the percentage of teachers participating in PD related to the content they teach increased from 59\% in 2000 to 83\% in 2004 and 87\% in 2008 (Wei, Darling-Hammond, \& Adamson, 2010).

Notable are the disappointing results of several other large-scale randomized control trials that tested PD with the five features (e.g., Garet et al., 2008; Garet et al., 2011). These studies have confirmed that it is not clear how to translate the five general features into effective practice.

There are ongoing studies into refining the five concepts towards more successful application based on a) changing procedural classroom behavior is easier than improving content knowledge or inquiry-oriented instruction techniques; (b) teachers vary in 
response to the same PD; (c) PD is more successful when it is explicitly linked to classroom lessons; (d) PD research and implementation must allow for urban contexts (e.g., student and teacher mobility); and (e) leadership plays a key role in supporting and encouraging teachers to implement in the classroom the ideas and strategies they learned in the PD.

Another trend, as discussed above, is the linking of PD to teacher evaluations. This is becoming more and more common, and it is driving improvements in how we organize, administer, and evaluate PD. Principals are increasingly including in their yearly evaluations measures of how well teachers are implementing the knowledge and practice they learned in PD. This creates a more coherent policy cycle, where the PD activities teachers engage in are explicitly valued and monitored by their school leaders and become a formal part of the evaluation system.

A third new direction in PD is the increased use of video as a tool for classroom observation and coaching. For example, the availability of new, low-cost video technology has made it possible for teachers' classes to be videotaped multiple times over a school year and then coded by a distant coach. A study by Allen and colleagues (2011) has shown potentially positive effects of video-based coaching on teachers' classroom instruction and student achievement.

Research has highlighted the development, resourcing and delivery, and the teaching and learning environment across the school education spectrum impacts PD. Darling-Hammond et al. (2017) support this conclusion in outlining that inadequate resourcing for PD-including needed curriculum materials-frequently exacerbates inequities and hinders school improvement efforts. Failure to align policies toward a coherent set of practices is also a major impediment, as is dysfunctional school culture. Implementing effective PD well also requires responsiveness to the needs of educators and learners and to the contexts in which teaching and learning will take place.

Following a study of 4 th to $6^{\text {th }}$ - grade teachers, Bucznyski and Hansen (2010) discussed several barriers to the implementation of PD. They note, "... teachers that are willing to implement professional development practices in the classroom often face hurdles that are beyond their control. The importance of recognizing barriers for teachers in the application of $P D$ may be a relevant consideration. The study's authors noted that lack of resources was the largest barrier to PD implementation, commenting that teachers often have to pay for their own materials for their classrooms. When considering PD for teachers, it is evident that consideration of the effectiveness of application of PD in the classroom may depend in some measure on the environment in which is applied."

Bautista et al. (2015). discuss the professional development of teachers in Singapore provided by the National Institute of Education, the Singapore Teachers' Academy. They align professional development with teachers' interests, school needs, and national curricula based on a 'Teacher Growth Model' whereby each teacher must complete 100 hours of development and training in an academic year. The PD activities are varied including formal courses, informal initiatives, action research activities, and case studies. Furthermore, the article emphasizes the importance of career advancement 
and the development of teachers' skills in relation to their specializations and teaching methods. The study also suggests that professional development models must be examined continuously to verify their effectiveness and the beneficial value to students. The study indicates that the Singaporean model is successful due to many factors within three levels; the state level, including society and politics, the level of organizations, as well as the family level (Dimmock \& Tan, 2013; Hairon \& Dimmock, 2011; Tan \& Dimmock, 2014). The teacher training model in Singapore is based on the following foundations: a) It has specialized training and is related to teaching activities within the classroom b) Continuous and intensive c) Provides teachers with the opportunity for active learning $\mathrm{d}$ ) Based on the needs and interests of teachers.

The PD model includes face-to-face training, online courses, conferences and seminars, procedural research, mentoring and coaching, and masters and doctoral programs. School principals hold a meeting with teachers in the presence of department heads to discuss the annual professional development plan in line with the teachers' needs, interests, school needs, and the national agenda.

Three development tracks were highlighted in the study. The first is the teaching track in which the participant reaches the level of an expert teacher or school principal. Then educational leadership, in which the participant reaches the level of senior management in education directorates. Finally, the third track in which teachers specialize in action research and educational policies.

Despite all resources and researches support, the study raises some challenges the Singaporean model is facing. It referred to the difficulty of measuring the PD impact due to the great diversity of activities and the presence of a huge number of variables as the plans are individual and different from one teacher to another and from one school to another. There is limited access to the resources in the subject matter training, also. For example, teachers from some primary schools are often allowed to attend PD related only to the subject matter of their specialization (e.g. mathematics), even though most of them teach a myriad of other subjects (e.g., music, arts).

Another challenge is related to high-stake examinations. The Singapore education system is highly competitive and selective (Hogan \& Gopinathan, 2008). Due to the pressure for students to be academically successful which is extremely well valued in local society and test scores are considered when being evaluated. Therefore, teachers in Singapore feel under pressure to 'teach to the test' and as a result, omit practices learned in PD training in their classroom practice.

C. Fraser et al. (2007) in an article "Teachers' continuing professional development: contested concepts, understandings and models" included remarks from (Bell \& Gilbert, 1996; Clarke \& Hollingsworth, 2002) who suggested professional development can be thought of as comprising personal, social and occupational aspects that are inter-related. This in turn may imply the impetus for change originates within the personal aspect of professional learning. Thereafter, development within the personal aspect can be encouraged or restrained by a range of factors (Wellcome Trust, 2006). Attitudes to professional learning have been found to vary across school sectors and subject areas. 
In addition, there are social aspects that support personal learning: learning isolation is seen as 'problematic', communities of practice are advocated as one way forward in this regard as members of the community are mutually engaged in a common enterprise, building up a shared repertoire of communal resources and have a social dimension (Bell \& Gilbert, 1996). Schools are potential communities of practice both for teachers and pupils, whereby opportunities for collaboration with colleagues exist and where interpreting information and making meaning can result in mediation of new knowledge within the community (Falk \& Dierking, 2000).

Fraser et al. (2007) summarized stating the following conditions are deemed very important in teacher's development under each of three aspects:

- Personal

- Teachers' beliefs, values and attitudes are important considerations.

- Interest and motivation need to be addressed.

- Social

- Relationships between individuals and groups need nurturing.

- Contexts need to be supportive to allow enactment and risk-taking.

- Occupational

- Links between theory and practice need to be strong.

- Intellectual stimulation and professional relevance are required.

It was also noted it is important to recognize that delivery 'style' and opportunity 'type' attend to these aspects in different ways and to varying extents.

\section{Findings}

According to a study done by Wei, Darling-Hammond \& Adamson (2010), the U.S. has significantly increased the number of teachers attending professional development. Between the years 2000 and 2008, the attendance percentage to professional development seminars increased from $59 \%$ to $87 \%$ respectively. This is evidence that the U.S. is heavily invested in the professional development of their teachers. The focus is on five core features as earlier mentioned, these are projected to be the guiding supports and pillars in the educator's professional development. It is however not clear how the five core features will be effectively implemented to positively impact the students' and the educators' experiences. This means that additional research on the concept is required to further describe how PD can be successfully incorporated into the education curriculum and what guidelines will be used.

Research shows that for PD to work, it has to be done right. Resources that facilitate the PD program should be availed for it to be successful. Constant monitoring of the process is necessary to identify problem areas that hinder or delay the program from working as expected. Monitoring will be used to build on a better approach to the PD. Additionally, appropriate policies should be formulated and applied. Extensive collaboration with all stakeholders is necessary so that they can all join in supporting the PD model being cultivated without which, the program could fall apart. 
In Singapore, PD is a critical part of a teacher's career, their system incorporates $\mathrm{PD}$ in that the teacher is required to complete a certain number of hours in development and training every year (Bautista et al. 2015). A 'Teacher Growth Model' combines numerous activities that are solely aimed at improving the effectiveness of the PD program. The program owes its success to several factors as discussed by (Dimmock \& Tan, 2014). The most significant factor is the deep integration of the program into the country's social-political systems. The PD system employed by Singapore is highly structured in that there is a wide range of resources and platforms. The system is consistently monitored by the national education department to ensure that it is in line with the national agenda.

The PD model used in Singapore is not without major setbacks as several studies indicate. This is mainly attributed to the numerous aspects that affect the impact of the program. This renders it impossible to accurately measure the effectiveness of the program. Tracking of the variables involved can be useful in helping to monitor the program better. According to Fraser et.al (2007), personal, social, and occupational aspects are the key factors that affect a teacher's development in their career.

\section{Recommendations}

This section draws from the findings stated above, it uses the insights gathered to come up with ideas that when implemented, will facilitate a PD to work effectively. The recommendations are based on well-researched studies conducted by competent researchers. The first recommendation would be the setting up of a highly structured framework that will support a PD program. A PD program as indicated requires the integration of very key players in the industry. The framework should clearly outline what is expected of the key players to ensures that roles are not neglected.

Establishment of efficient and effective ways to monitor the PD program. Monitoring progress is a very crucial step this will identify issues that could ruin or in another way distract the program. This will enable the stakeholders to identify the upsides and downsides encountered in the process. Monitoring should be assigned to a diverse team that has different capabilities in education and other sectors. This will ensure that the program is appropriately monitored.

Extensive involvement of educators in the planning, implementation, basically all the steps of the program lifecycle. Teachers being the key personnel in the program, have a right to be fully involved in the process. They can offer insights, advice, and their experiences to appropriately advise on what is the best course of action for the program as they are the expertise in the field. A sense of ownership will go a long way in encouraging educators to support the program. The commitment of educators to the program is key to the success of the program.

The unwavering solid support of the program by the government is essential for the success of the PD. The program requires resources without which it will fail means wide open recourse for the program. The resources could be; training materials, 
motivations, remuneration, and funding. Additionally, policies should be put in place and followed through to secure the interests of the program.

Stakeholders should ensure that the program model is constantly being reviewed in order to improve it over time whenever the need arises. This means that the program will be altered to overcome its shortcomings and to align itself with the needs. The education environment is ever-changing and therefore, those changes should be reflected in the PD for it to be more effective and efficient.

\section{Conclusion}

PD is an essential program that enriches the education system. It is no brainer that learners stand to gain more from an educator who has undergone numerous professional development courses. Bearing in mind that the program is continuous, this translates to a better quality of education. This program has the potential to transform the education scene when supported by all industry players.

Policy plays a vital role in the success of programs like PD. Policies surrounding the government of this program should be carefully structured to guide the program appropriately as well as formulators should be industry players who understand the drivers that affect the education sector and in particular the educators. Good policy choices will mean that the program stands a chance to be effective.

The program should be provided with all the necessary resources for it to be effective and to enable smooth running, educators should be facilitated with the necessary materials they require for the program. Lack of resources means that the program will not achieve its intended goals. Resources might be learning resources for the educator, allowances among many others.

Extensive collaborations should be done by the sectors that could play a strong role in affecting the education, stakeholders, investors and other parties related in order to reach an agreement on the best model of PD. Additionally, there is a need to determine how best to run the program to be beneficial to the education system.

\section{Conflict of Interest Statement}

Abdulla Al Darayseh, Sultan Al Sadi, and Yahia Alramamneh declare that they have no conflict of interest.

\section{About the Authors}

Abdulla Al Darayseh, Learning and Development Department, Science Education and Teachers Professional Development.

Sultan Al Sadi, Learning and Development Department, Math Education and Teachers Professional Development.

Yahia Alramamneh, Learning and Development Department, Arabic Education and Teachers Professional Development. 


\section{References}

Al-Dossary, A. (2020). International handbook of teacher education training $\mathcal{E}$ re-training system in modern world.

Allen, J. P., Pianta, R. C., Gregory, A., Mikami, A. Y., \& Lun, J. (2011). An interactionbased approach to enhancing secondary school instruction and student achievement. Science, 333(6045), 1034-37.

Bautista, A., Wong, J., Gopinathan, S. (2015). Psychology, society, \& education. 7(3), 311326. DOI: $10.25115 /$ psye.v7i3.523

Bell, B. G., J. (1996). Teacher development: A model from science education. Falmer Press.

Canagarajah, S. (2015). TESOL as a professional community: A Half-Century of pedagogy, research, and theory. Tesol Quarterly, 50(1) https://doi.org/10.1002/tesq.275

Clarke, D. H., H. (2002). Elaborating a model of teacher professional growth. Teaching and Teacher Education, 18(8), 947-967.

Darling-Hammond, L., Hyler, M. E., Gardner, M. (2017). Effective teacher professional development. Learning Policy Institute.

Desimone, L. M., \& Garet, M. S. (2008). The impact of two professional development interventions on early reading instruction and achievement. Best Practices in Teachers' Professional Development in the United States, 7(3), 252-263.

Falk, J. H. \& Dierking, L. D. (2002). Learning from museums: Visitor experiences and the making of meaning. AltaMira Press.

Fielding, Glen D., Schalock, H. Del \& Oregon Univ., Eugene. Center for Educational Policy and Management \& ERIC Clearinghouse on Educational Management. (1985). Promoting the professional development of teachers and administrators. ERIC Clearinghouse on Educational Management.

Frasera,C., Kennedy, A., Reid, L. \& Mckinney, S. (2007). Teachers' continuing professional

development:

Contested

concepts, understandings and models. Journal of in-Service Education, 33(2), 153-169.

Ganser, T. (2000). An ambitious vision of professional development for teachers. NASSP Bulletin, 84(618), 6-12. https://doi.org/10.1177/019263650008461802

Garet, M., Wayne, A., Stancavage, F., Taylor, J., Eaton, M., Walters, K., \& Doolittle, F. (2011). Middle school mathematics professional development impact study: Findings after the second year of implementation (NCEE 2011-4024). Washington, DC: U.S. Department of Education.

Glatthorn, A. (1995). Teacher Development In: Anderson, L. (ed.), international encyclopedia of teaching and teacher education (second edition ed.). Pergamon Press.

Sahlberg, P. (2016). The global educational reform movement and its impact on schooling. John Wiley \& Sons, Ltd. https://10.1002/9781118468005.ch7

U.S. Department of Education. (2012). National center for education statistics, schools and staffing survey (SASS), public and private teachers data file. 
Wei, R, C., Darling-Hammond, L., \& Adamson, F. (2010). Professional development in the United States: Trends and challenges.

Wellcome Trust (2006). Believers, seekers and sceptics. to copy, distribute, transmit or adapt the article content, providing a proper, prominent and unambiguous attribution to the authors in a manner that makes clear that the materials are being reused under permission of a Creative Commons License. Views, opinions and conclusions expressed in this research article are views, opinions and conclusions of the author(s). Open Access Publishing Group and European Journal of Education Studies shall not be responsible or answerable for any loss, damage or liability caused in relation to/arising out of conflicts of interest, copyright violations and inappropriate or inaccurate use of any kind content related or integrated into the research work. All the published works are meeting the Open Access Publishing requirements and can be freely accessed, shared, modified, distributed and used in educational, commercial and non-commercial purposes under a Creative Commons Attribution 4.0 International License (CC BY 4.0). 